\title{
IMPROVING ENERGY AND ENVIRONMENTAL EFFICIENCY OF COMBINED HEAT-AND POWER PLANT BASED ON ABSORPTION HEAT TRANSFORMERS
}

\author{
Yu. V. Yavorovsky ${ }^{1}$, A. I. Bartenev ${ }^{1}$, I. A. Sultanguzin ${ }^{1,}$, A Sh Alimgazin ${ }^{2}$, S. A. Prishchepova ${ }^{1}$, and I. D. Kalyakin ${ }^{1}$ \\ ${ }^{1}$ Moscow Power Engineering Institute, Moscow, Russia \\ ${ }^{2}$ Eurasian National University, Nur-Sultan, Republic Kazakhstan
}

\begin{abstract}
In the present paper the scheme for increasing the energy efficiency of combined heat and power plants (CHPP) using absorption heat transformers (AHT) is considered. The aim of the study is to increase the energy and environmental efficiency of natural gas use in power supply systems by application steam turbine plants and absorption heat transformers. The simulation of CHPP modernization and a harmful emissions dispersion assessment were carried out using the following software tools: ISC Manager, Thermoflex. All the calculations were made for one power unit of the CHPP in Moscow. Subsequently, the obtained data on energy efficiency increase and harmful emissions reduction were multiplied on the whole power system of Moscow, the main source of heat and electricity of which are the CHPP's of PJSC "Mosenergo".
\end{abstract}

\section{Relevance of the topic}

Energy-efficient and environmentally friendly production of heat and electric energy is the key to the development of society and improving people's living standards.

Depreciation of the main equipment of the energy sector is the main reason for the increased costs of generating energy resources, as well as an increase in harmful emissions.

The development of CHPP schemes to reduce fuel consumption and the amount of emissions of harmful substances is a promising direction in the development of heat and electricity.

In world practice, there are examples of the use of absorption heat transformers at thermal power plants. These are coal stations in China, none of which can now be built without using AHT on them. China is currently a leader in the production of absorption heat transformers and a pioneer in the use of AHT at thermal power plants.

The main studies of the use of AHT at CHP plants were also conducted in China $[1,2,3,4,5]$. Unfortunately, these articles do not provide specific values for the magnitude of the energy effect from the use of AHT at CHP plants. In addition, there is no assessment of the environmental effect of reducing harmful emissions from thermal power plants.

It should be noted that articles [1-5] are based on data on coal-fired thermal power plants that are used in China, and there are practically no studies on the use of AHT on gas-fired thermal power plants specific to our region.
In this regard, modeling the modernization of a real thermal power plant to obtain reliable data on the energy and environmental effect of such modernization is a paramount task for the energy-efficient and environmentally friendly development of the fuel and energy complex (FEC) of Moscow, in particular, and Russia as a whole.

As a first step to calculate the effect of the modernization of the CHPP, an analysis of the energy system of Moscow was carried out.

\section{Analysis of the energy system of Moscow}

To select the object of study, the heat and power supply system of Moscow was considered [6]. It was revealed that the main energy sources are Mosenergo CHPPs. Figures 1 and 2 show the distribution of the installed electric and heat capacities of the CHPPs in Moscow. 


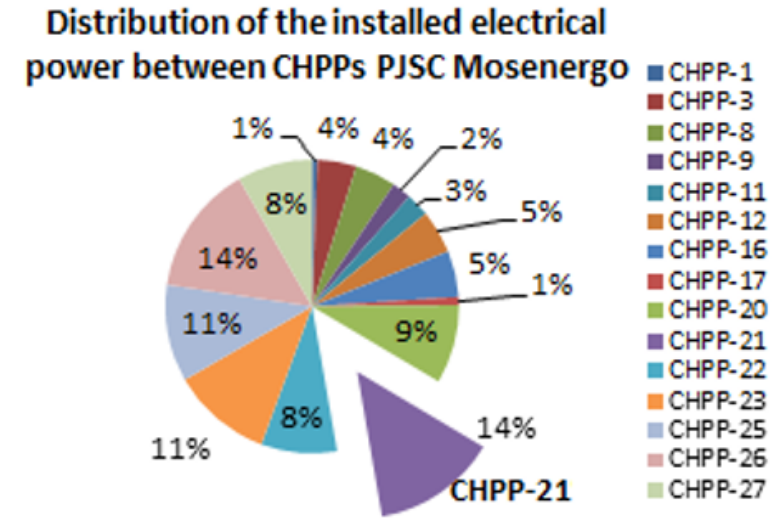

Fig. 1. Distribution of the installed electrical power between CHPPs PJSC Mosenergo.

\section{Distribution of the installed heat power between CHPPs PJSC Mosenergo}

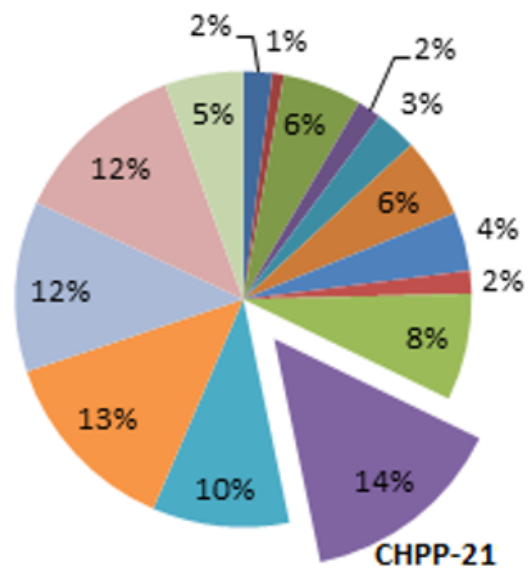

$=$ CHPP-1
$=$ CHPP-3
$=$ CHPP-8
$=$ CHPP-9
$=$ CHPP-11
$=$ CHPP- 12
$=$ CHPP-16
$=$ CHPP- 17
$=$ CHPP-20
$=$ CHPP-21
$=$ CHPP-22
$=$ CHPP- 23
$=$ CHPP-25
$=$ CHPP-26
$=$ CHPP- 27

Fig. 2. Distribution of the installed heat power between CHPPs PJSC Mosenergo.

As can be seen from the diagram presented in Figure 1, CHPP-21, along with CHPP-26, is one of the largest in terms of installed electric capacity. The diagram in Figure 2 demonstrates that the installed heat capacity of CHPP-21 is the largest. This makes it a suitable object for modeling modernization, since installing an AHT on it, presumably, can lead to a greater energy and environmental effect.

Thermal Power Station №21 is a typical heat and power plant for Moscow, since its equipment includes power units with a pressure of $130 \mathrm{~atm}$, more modern ones with a pressure of $240 \mathrm{~atm}$, as well as a combined cycle gas turbine unit commissioned in 2008. CHPP-21 is located in the Northern Administrative District of Moscow. It supplies thermal energy to residents of the Northern, North-Eastern and Central administrative districts of Moscow, as well as Khimki, Moscow Region.

Along with the energy effect, an important factor determining the efficiency of modernization of thermal power plants using AHT is the reduction of harmful emissions as a result of modernization. In the work, the calculation of the dispersion of emissions from the CHPP before and after modernization was performed.

\section{Polluting emissions}

To assess the impact of emissions of harmful substances on the population, the Impact Pathways methodology is used [7, 8]. The basis of this methodology is the implementation of the following steps [9]:

- Source selection (emission determination)

- Calculation of dispersion of harmful emissions (increase in concentration)

- Calculation of exposure (dose-effect function)

- Economic damage assessment (cost).

This methodology allows estimating the emissions of harmful substances into the atmosphere, pollution of water bodies and soil.

To determine the environmental impact of harmful emissions, ISC Manager software was used [7], which calls the Industrial Source Complex (ISC) program to calculate dispersion. ISC is recommended for use by the US Environmental Protection Agency (EPA). It is based on the statistical theory of dispersion of harmful emissions in the atmosphere, based on the assumption that the distribution of the concentration of impurities in a diffusing cloud of smoke is determined in accordance with the Gauss law. To display the calculation results, ISC Manager uses the GIS "Map 2008" geographic information system.

As a function of the "dose-effect", the results of medical research are used, which are carried out in many countries of the world separately for each pollutant and for each physical effect. To determine the total physical impact in the region, the ISC Manager program calculates the population density and determines the effect of the increase in surface concentration of harmful substances on the deterioration of public health in accordance with the dose-effect function $[7,8]$.

To calculate the values of emissions of harmful substances from CHPPs of PJSC Mosenergo, information was collected on the number of chimneys of TPPs, their height, and also the annual emission of harmful substances into the atmosphere [10].

As a result of the simulation, it was found that the maximum concentration of emissions of nitrogen oxides $(6.32 \mu \mathrm{g} / \mathrm{m} 3)$ and carbon oxides $(0.28 \mu \mathrm{g} / \mathrm{m} 3)$ is achieved in the district of CHPP-21. The maximum permissible concentration for these pollutants is 0.06 and $3.0 \mathrm{mg} / \mathrm{m} 3$, respectively. The dispersion and impact of nitrogen oxide emissions is shown in Figures 3 and 4. The maximum impact ( 0.0223 units) is achieved in close proximity to CHPP-21, which makes reducing its emissions an urgent task. 


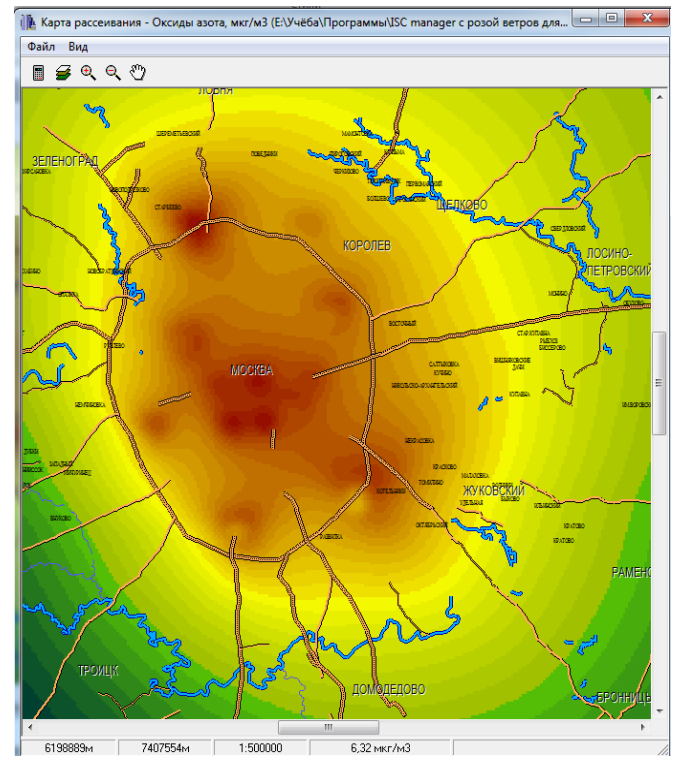

Fig. 3. Map of the dispersion of nitrogen oxides from the CHPPs of PJSC Mosenergo.

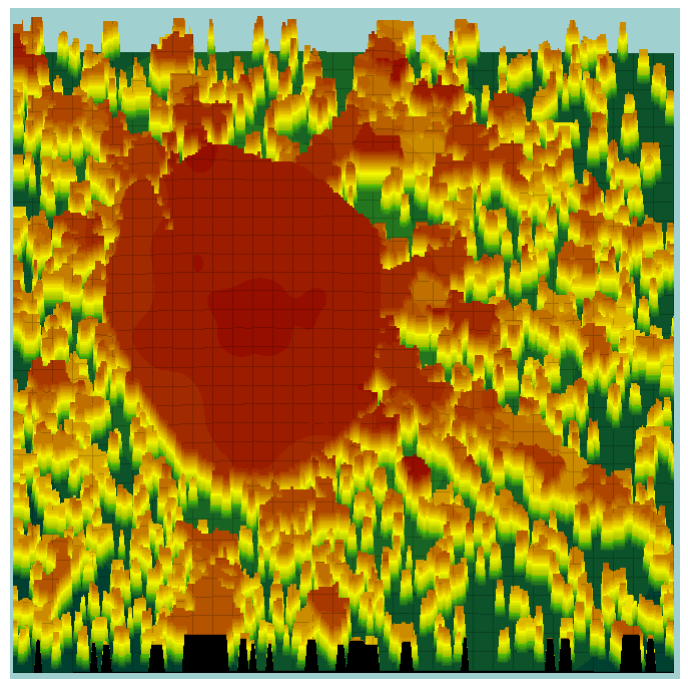

Fig. 4. Three-dimensional matrix of the effect of nitrogen oxides on the population from the CHPPs of PJSC Mosenergo.

Summary data on the effects of harmful emissions from CHPPs on the population of Moscow are presented in table 1.

Table 1. Damage from emissions of harmful substances from CHPPs of PJSC Mosenergo.

\begin{tabular}{|c|c|c|}
\hline Pollutants & $\begin{array}{c}\text { Mortality, } \\
\text { ppl / year }\end{array}$ & $\begin{array}{c}\text { Damage, million rubles / } \\
\text { year(Cost of average life } \\
=\mathbf{6 8} \text { million rubles) }\end{array}$ \\
\hline SOx & 39,97 & 2717,96 \\
\hline Solids & 29,18 & 1984,24 \\
\hline CO & 0,15 & 10,20 \\
\hline NOx & 160,42 & 10908,56 \\
\hline In total & 229,72 & 15620,96 \\
\hline
\end{tabular}

To assess the energy effect of the proposed modernization, it is necessary to consider in more detail the schemes of thermal power plants before and after modernization and the procedure for their calculation.

\section{Structural schemes of thermal power plants before and after modernization}

Figure 5 shows the initial simplified scheme of the CHPP [11]. Steam turbine, steam turbine. After triggering in the high-pressure cylinder (HPC), part of the steam enters the low-pressure cylinder (LPC). After the LPC has exhausted steam, it enters the condenser, from where, after condensation, the circulation pump is pumped back to the boiler. The condenser cooling circuit consists of a cooling tower and a pump. Part of the steam after the HPC is sent to the steam-water heat exchanger, where it condenses and fed back into the circuit. Water from the heated circuit of the steam-water heat exchanger is pumped to the water heat exchanger, which is installed at the central heating statiion (CHS), and then fed back to the steam-water heat exchanger.

The heat consumer circuit consists of water heat exchanger, a pump and the heat consumer itself.

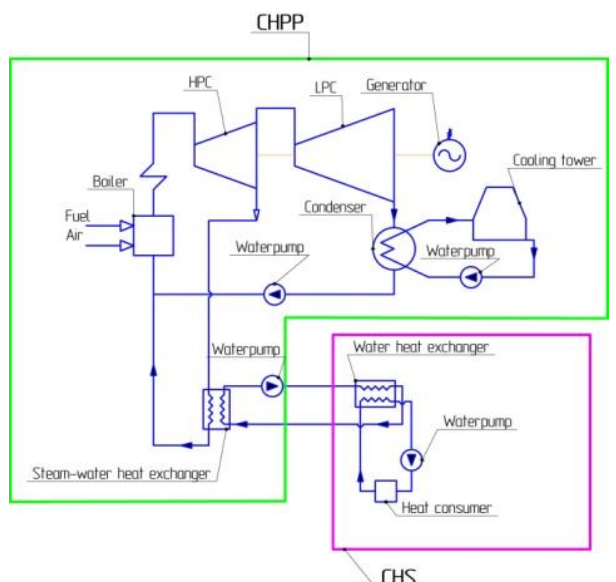

Fig. 5. Simplified CHPP scheme.

The modernized scheme of the CHPP shown in Figure 6 additionally includes two AHTs (at the CHPP and CHS). The main circuit works without changes.

Part of the steam from the selection of HPC is sent as a heating source to the AHT installed at the CHPP. Water from the condenser cooling circuit, taken in front of the cooling tower, acts as the AHT cooling medium. At the same time, part of the water taken in front of the tower from the condenser cooling circuit enters the AHT for cooling. After heating in the AHT, the cooling water is directed to the steam-water heat exchanger, where it is heated and then pumped to the AHT installed on the central heating station, where it acts as a heating coolant.

The heating water from the CHPP, passing through the AHT, transfers part of its thermal energy and then enters the water-water heat exchanger, where it also acts as a heating coolant. After the heat exchanger, water from the CHPP is sent back to the AHT, but already as a cooled coolant. After AHT, chilled water is directed to the cooling circuit of the CHPP condenser, while mixing with part of the water that was previously supplied to the AHT for cooling [12].

The use of AHT at CHPPs and CHS will allow to utilize the low-temperature waste heat of the condenser by changing the temperature schedule of the main 
networks from $120 / 70{ }^{\circ} \mathrm{C}$ to $120 / 20{ }^{\circ} \mathrm{C}$, while the temperature schedule of consumers changes from $95 / 70$ ${ }^{\circ} \mathrm{C}$ to $60 / 40{ }^{\circ} \mathrm{C}$. Utilization of the condenser waste heat is achieved by supplying reverse network water from the line to the condenser cooling circuit, after which this water is heated in the AHT and the steam-water heat exchanger and is fed back to the heat consumers.

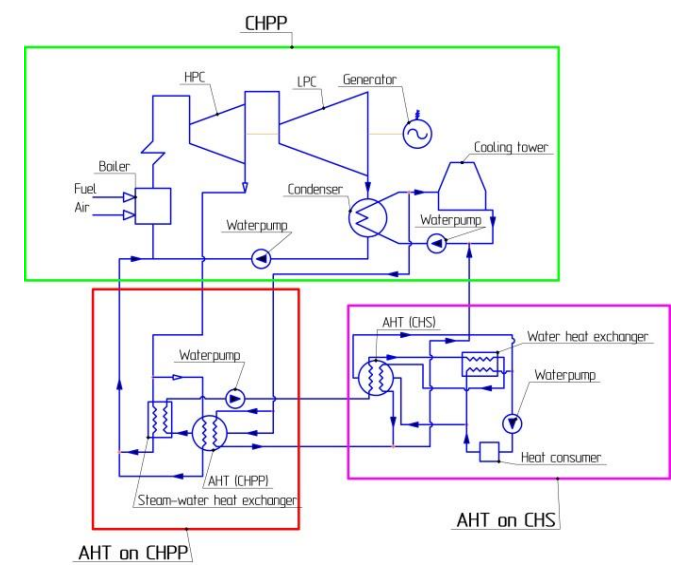

Fig. 6. Simplified CHPP scheme with AHT.

Two steam-turbine power units with a pressure of $240 \mathrm{~atm}$ were selected as the object for modeling the use of AHT at the CHPP, as the most modern and powerful at the station. To simplify the calculation process, the construction of CHPP models was performed using the Thermoflex software package.

Thermoflex is a universal program. The objects of modeling can be gas turbine units (GTU), GTU with recovery boilers, combined cycle plants (CCP) with recovery boilers, CHPP, CCGT with coal gasification, water desalination plants, steam power plants on solid, liquid and gas fuel, cogeneration systems, biomass power plants, solar and nuclear power plants, waste incinerator power plants, Kalina cycles, organic Rankine cycles, etc. [13].

The models of the initial and modernized circuits are shown in Figures 7, 8, 9, 10. Due to limitations in the program by the number of elements, the model of the modernized thermal power plant circuit with AHT was divided into 3 parts.

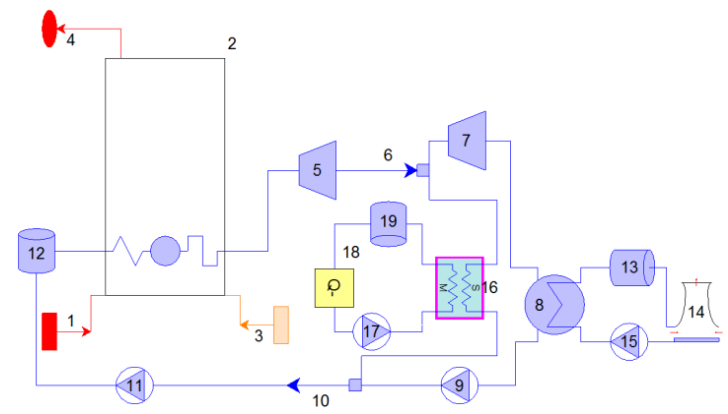

Fig. 7. Simplified CHPP model (1 - air source; 2 - boiler; 3 fuel source; 4 - exhaust; 5 - HPC; 6 - stream splitter; 7 - LPC; 8 - condenser; 9 - water pump; 10 - stream connector; 11 - water pump; 12 - element for setting the type of coolant; 13 - element for setting the type of coolant of the condenser cooling circuit; 14 - cooling tower; 15 - circulation pump of the condenser cooling circuit).

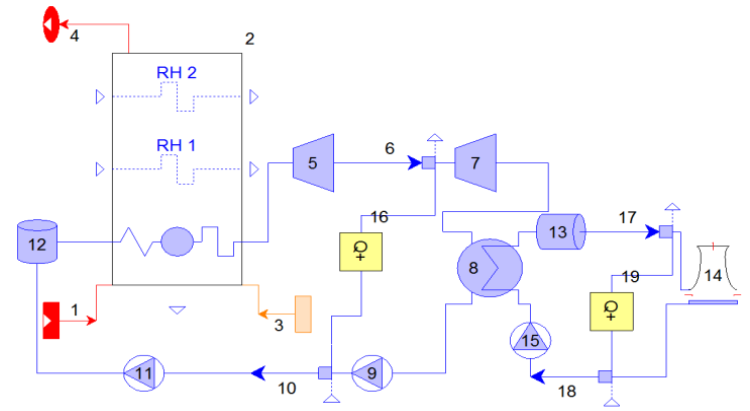

Fig. 8. Simplified CHPP model with AHT (part 1) (1 - air source; 2 - boiler; 3 - fuel source; 4 - exhaust; 5 - HPC; 6 stream splitter; 7 - LPC; 8 - condenser; 9 - water pump; 10 stream connector; 11 - water pump; 12 - element for setting the type of coolant; 13 - element for setting the type of coolant of the condenser cooling circuit; 14 - cooling tower; 15 circulation pump of the condenser cooling circuit. 16 connecting element of the steam circuit of the CHP and the ATT circuit at the CHP (Figure 9, elements 1 and 4); 17 stream splitter; 18 - stream connector; 19 - a connecting element of the condenser cooling circuit and the ATT circuit at the TPP (Figure 9, element 12)).

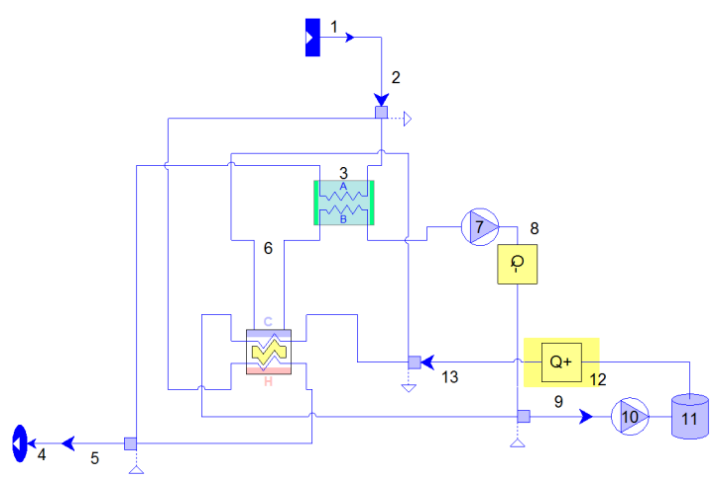

Fig. 9. Simplified CHPP model with AHT (part 2) (1 - steam from the selection of HPC (entry to element 16 of figure 8); 2 stream splitter; 3 - steam-water heat exchanger; 4 - return water to the boiler (exit from element 16 of figure 8 ); 5 - stream connector; 6 - AHT; 7 - pump; 8 - connecting element of the AHT circuit at the CHPP and the heat consumer circuit (Figure 10, elements 1 and 4); 9 - stream splitter; 10 - pump; 11 element for setting the type of coolant; 12 - a connecting element of the condenser cooling circuit and the AHT circuit at the CHPP (Figure 8, element 19); 13 - stream splitter).

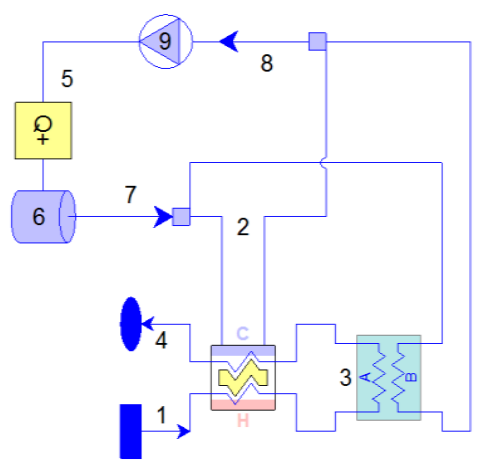

Fig. 10. 1 - hot water from the CHPP (input to element 8 of figure 9); 2 - AHT; 3 - water heat exchanger; 4 - return water to the CHPP (exit from element 8 of Figure 9); 5 - heat consumer; 6 - element for setting the type of coolant; 7 - stream splitter; 8 - stream connector. 
According to the simulation results, the annual savings from using AHT at a power unit with a pressure of 240 at CHPP-21 amounted to about $7.1 \%$ or 54.9 thousand tons of equivalent fuel per year.

Annual CO2 reduction for power unit 240 at. CHP21 amounted to 88.3 thousand tons per year, or about $7.09 \%$ of the total $\mathrm{CO} 2$ emissions. Based on the data obtained on reducing emissions during the modernization of CHPP plants, it is possible to assess the reduction in the impact on public health using the ISC Manager program.

\section{Emissions after modernization}

With the joint modernization of 130 at. and 240 at. harmful emissions will be reduced according to the data indicated in table 2 .

Table 2. Reducing emissions of harmful substances from CHPP-21 after modernization of power units 240 and 130 at, $t$ / year.

\begin{tabular}{|c|c|c|c|}
\hline $\begin{array}{c}\text { Polluta } \\
\text { nts }\end{array}$ & $\begin{array}{c}\text { Emissions } \\
\text { before } \\
\text { modernizati } \\
\text { on, } \mathbf{t} \text { / year }\end{array}$ & $\begin{array}{c}\text { Emissions } \\
\text { after } \\
\text { modernizati } \\
\text { on, } \text { / year }\end{array}$ & $\begin{array}{c}\text { emission } \\
\text { reduction }\end{array}$ \\
\hline Solids & 0,0 & 0,0 & 0,0 \\
\hline SOx & 9,0 & 8,4 & 0,6 \\
\hline NOx & 3726,0 & 3461,8 & 264,2 \\
\hline CO & 174,0 & 161,7 & 12,3 \\
\hline In total & 3909,0 & 3631,9 & 277,1 \\
\hline
\end{tabular}

The obtained data can be multiplied to other thermal power plants of PJSC Mosenergo and, thus, to a first approximation, obtain the energy and environmental effects from the modernization of the main sources of thermal and electric energy in Moscow

\section{Multiplication of simulation results at the CHPP of Mosenergo}

The annual fuel consumption for all CHPPs of PJSC Mosenergo amounted to 23,327 thousand tons of equivalent fuel. With the use of AHT at all CHPPs plants in Moscow, annual savings of $7.1 \%$ will reduce fuel consumption by 2,809 thousand tons of equivalent fuel. or, of the order, 2,442 million $\mathrm{m} 3$ of natural gas, which at a gas price of 4,694 rubles / thousand $\mathrm{m} 3$ will save 11,463 million rubles a year.

Analysis of the results allows us to draw the following conclusions:

1. The use of AHT at CHPPs and central heating plants leads to a transition to lower coolant temperatures in heat supply systems, which confirms the trend that has emerged in many countries of the world.

2. This modernization allows to reduce the load on the cooling tower, which leads to lower thermal pollution, another important environmental effect.
The use of AHT makes it possible to increase the supply of thermal energy without upgrading the power equipment of a thermal power plant.

To assess the reduction in the impact of harmful emissions from the Mosenergo CHPPs on the population, using the results of modeling of modernization of the power unit 240 at.

Table 3 presents data on economic damage from operation.

Table 3. Damage from emissions of harmful and polluting substances from the CHPPs of PJSC Mosenergo.

\begin{tabular}{|c|c|c|c|c|}
\hline $\begin{array}{c}\text { Poll } \\
\text { uta } \\
\text { nts }\end{array}$ & $\begin{array}{c}\text { Mortality } \\
\text { before } \\
\text { moderniz } \\
\text { ation, ppl } \\
\text { / year }\end{array}$ & $\begin{array}{c}\text { Mortality } \\
\text { after } \\
\text { moderniz } \\
\text { ation, ppl } \\
\text { / year }\end{array}$ & $\begin{array}{c}\text { Differenc } \\
\text { e, ppl / } \\
\text { year }\end{array}$ & $\begin{array}{c}\text { Damage } \\
\text { reduction } \\
\text {, million } \\
\text { rubles / } \\
\text { year }\end{array}$ \\
\hline SOx & 39,97 & 3,58 & 36,39 & 2475 \\
\hline $\begin{array}{c}\text { Soli } \\
\text { ds }\end{array}$ & 29,18 & 0,12 & 29,06 & 1976 \\
\hline CO & 0,15 & 0,14 & 0,01 & 0,7 \\
\hline $\begin{array}{c}\text { NO } \\
\text { x }\end{array}$ & 160,42 & 125,38 & 35,04 & 2383 \\
\hline $\begin{array}{c}\text { In } \\
\text { tota } \\
\text { I }\end{array}$ & 229,72 & 129,22 & 100,50 & 6834 \\
\hline
\end{tabular}

The data presented in table 3 give a clear idea of the environmental effect of modernization using AHT of all CHPPs plants owned by Mosenergo PJSC. The modernization method presented in this work is effective not only in terms of energy efficiency, but also from an environmental point of view. Damage reduction during modernization of all CHPPs amounts to 6,834 million rubles per year.

\section{Conclusion}

Reducing fuel consumption by a 240 at power unit is amounted to $7.1 \%$ or 54.9 thousand tons of equivalent fuel per year, which, with a gas price of 4.7 rubles per $\mathrm{m} 3$, will save about 224 million rubles per year. With the joint modernization of power units 130 and 240 at, the savings will be about 180 thousand tons of fuel equivalent per year, which is equivalent to 733 million rubles per year.

It is also necessary to pay attention to reducing damage from the effects of harmful emissions from CHPP-21. With the modernization of the 240 at power unit, the damage reduction will be 21 million rubles / year, and with the joint modernization of the 240 and 130 at power units, the damage reduction will be 69 million rubles per year.

Multiplication of the results obtained in the work shows that the application of the proposed technology will bring significant energy and environmental effects and will reduce fuel consumption by 2809 thousand tons of equivalent fuel. or, of the order, 2,442 million $\mathrm{m} 3$ of natural gas, which at a gas price of 4700 rubles per thousand. $\mathrm{m} 3$ will save 11,463 million rubles a year.

Emissions from CHPPs lead to mortality of about 300 people per year, which entails damage in the amount 
of 15620 million rubles per year. A decrease in these indicators is a prerequisite for the development of a heat supply system.

From an environmental point of view, such modernization will reduce emissions of harmful substances by 45,000 tons per year, which will reduce mortality by 101 people per year, and taking into account the cost of average life in monetary terms, it will save 6,868 million rubles per year.

The proposed modernization will reduce the consumption of fuel and energy resources at thermal power plants, and will also favorably affect the environmental situation in Moscow, which makes it a promising way to modernize existing CHPPs.

\section{References}

[1] S. Jian, F. Lin, Zh. Shigang, Experimental study of heat exchanger basing on absorption cycle for CHP system, Applied Thermal Engineering 102, 1280-1286 (2016)

[2] H. Tianle, X. Xiaoyun, J. Yi, Simulation research on a variable-lift absorption cycle and its application in waste heat recovery of combined heat and power system, Energy 140, 912-921 (2017)

[3] X. Xiaoyun, J. Yi, Absorption heat exchangers for long-distance heat transportation, Energy 141, 2242-2250 (2017)

[4] S. Jian, F. Lin, S. Fangtian, Z. Shigang, Experimental study on a project with CHP system basing on absorption cycles, Applied Thermal Engineering 73, 1, 732-738 (5 December 2014)

[5] H.S. Zhang, H.B. Zhao, Z.L. Li, Performance analysis of the coal-fired power plant with combined heat and power (CHP) based on absorption heat pumps, Journal of the Energy Institute 89, 70-80 (2016)

[6] Updating the heat supply scheme of the city of Moscow for the period until 2032. Approved by order of the Ministry of Energy of the Russian Federation of 19 March 2019, No. 249 (2019)

[7] I. Sultanguzin, Environmental Safety and Energy Efficiency of Industrial Heat and Power Systems: a Training Manual (Publishing House MPEI, 288, 2013)

[8] A. Rabl, J. Spadaro, M. Holland, How Much Is Clean Air Worth? Calculating the Benefits of Pollution Control (Cambridge University Press, 671, 2014)

[9] I. Sultanguzin, The application of the methodology of the sequence of environmental impacts of harmful emissions in industrial power engineering: a methodological manual (Publishing House MPEI, 48, 2013)

[10] Preparation of the initial information necessary for the formation of the consolidated fuel and energy complex of Moscow, The report on the 1 st stage as part of the work under state contract no. 9 P4 / 01/0173200001116000223 of 27 September 2016, Moscow, 271 (2016)

[11] V. Ryzhkin, Thermal Power Stations: A Textbook for High Schools (Energoatomizdat, 328,1987 )

[12] A. Bartenev, S. Prishchepova, I. Sultanguzin, Evaluation of the effectiveness of using AHT at CHPPs and central heating plants in heat supply systems, Proceedings of the ninth international school - a seminar for young scientists and the specialist Energy Saving - Theory and Practice (Publishing House MPEI, 163-166, 2018)

[13] A. Fedyukhin, I. Sultanguzin, S. Kurzanov, R. Belov, A. Bakulin, T. Shomova, Application of applied software for solving industrial heat power problems: a training manual (Publishing House MPEI, 88, 2016)

[14] THERMOFLEX. Fully-Flexible Heat Balance Engineering Software, Thermoflow, Inc, THERMOFLEX User's Manual 3, 1139 (February 2013)

[15] User's Guide for the Industrial Source Complex (ISC3) Dispersion of Model Algorithms [Electronic resource] (US Environmental Protection Agency 2, 1995). Available at: http://www.epa.gov/scram001/userg/ $\mathrm{regmod} /$ isc3v2.pdf 